\title{
EFEK "PAKET MISERI" TERHADAP KEMAMPUAN IBU HAMIL DALAM MELAKUKAN PENCEGAHAN DINI MALARIA DI KABUPATEN JAYAPURA
}

\author{
Fathia Fakhri Inayati Said ${ }^{1)}$, Irna Nursanti ${ }^{2)}$, Natsir Nugroho ${ }^{3)}$ \\ 1.Mahasiwa Program magister Keperawatan Fakultas Keperawatan Muhammadiyah Jakarta, \\ Stikes Jayapura \\ 2.3. Dosen Program magister Keperawatan Fakultas Keperawatan Muhammadiyah \\ Jakarta \\ E-mail :info@fikumj.ac.id
}

\begin{abstract}
ABSTRAK
Kejadian penyakit malaria masih menduduki urutan keempat dari sepuluh penyakit infeksi di Kabupaten Jayapura. Menurut data penyakit malaria Dinkes Kota Jayapura pada tahun 2015 terdapat ibu hamil dengan malaria sebanyak 31 orang dan meningkat pada tahun 2016 sebanyak 79 orang (Depkes RI, 2016). Berdasarkan data Puskesmas Sentani (2018) tercatat jumlah ibu hamil dengan positif malaria sebanyak 56 orang.Tujuan dalam penelitian ini adalah untuk mengetahui "Efek Paket MISERI” Terhadap Kemampuan Ibu Hamil Dalam Melakukan Pencegah Dini Malaria di Kabupaten Jayapura.Penelitian ini adalah penelitian kuantitatif dengan desainQuasiEksperiment pre and post with control group. sampel yang digunakan berjumlah 70 responden yang dibagi menjadi 2 kelopok dengan masing-masing 35 responden. Analisis data menggunakan uji paired t-test menunjukkan hasilkelompok intervensi sesudah diberikan "Paket MISERI" berpengaruh secara bermakna dibanding kelompok kontrol. Dimana pada kelompok intervensi mendapat hasil p value =0,000<0,05. Saran bagi pelayanan kesehatan Perlunya membuat program promosi kesehatan yang dilakukan secara continue terhadap ibu hamil di wilayah endemis malaria menggunakan "Paket MISERI" dalam pencegahan dini malaria.
\end{abstract}

Kata Kunci: Paket Mi seri kemampuan, pencegahan dini malaria

\begin{abstract}
The incidence of malaria is still the fourth out of ten infectious diseases in Jayapura Regency. According to the data on malaria of the Health Services of Jayapura City in 2015, there were 31 pregnant mothers suffering from malaria and the number increased to 79 people in 2016 (Health Department of the RoI, 2016). Based on the data of Sentani Local Government Health Center (2018), the number of pregnant mother positively infected with malaria was 56 people. The purpose of this research was to know the "Effect of MISERI Package" to the Ability of Pregnant Mothers in Carrying Out Early Intervention for Malaria Prevention in Jayapura Regency, Papua. The method used was the quasi-experimental quantitative research with pretest and posttest with control group.The samples were 70 respondents divided into 2 groups respectively consisting of 35 respondents. The data analysis used the paired t-test indicated that after giving the "MISERI Package", the results of the intervention group showed that it had significant effect compared to the package of the control group. The intervention group obtained the $p$ value = $0.000<0.05$. Suggestion for health service organizing, it is necessary to create a health promotion program carried out continuously for pregnant women in malaria endemic areas using the "MISERI Package" in the course of early malaria prevention.
\end{abstract}

Keywords: Paket Mi seri kemampuan, pencegahan dini malaria 


\section{PENDAhUluan}

Program pemerintah dalam pengendalian penyakit Malaria masih menjadi target yang perlu perhatian khusus dimana Indonesia memiliki sebagian besar wilayah endemis malaria diantaranya Papua, Papua Barat, dan NTT (WHO 2017).

proses eliminasi malaria mengalami tantangan global terbesar dimana kurangnya pendanaan internasional dan domestik yang berkelanjutan, iklim anomaly, resiko yang ditimbulkan oleh zona daerah konflik, munculnya resistensi parasit terhadap obatobatan antimalaria dan resistensi nyamuk terhadap inseksida.

Malaria dapat menyerang siapapun tanpa membedakan umur, jenis kelamin, dan status sosial, begitu pula malaria dapat menyerang ibu hamil yang merupakan kelompok rentan terhadap infeksi. Infeksi malaria pada ibu hamil mudah terjadi sebab selama kehamilan terjadi perubahan sistem imun baik imunitas seluler maupun hormonal dan diduga penyebabnya adalah meningkatnya hormon kortisol sehingga wanita hamil yang berada pada daerah endemis akan rentan terhadap infeksi parasit malaria dibandingkan dengan ibu yang tidak hamil (Rusdji, 2012).

Malaria pada kehamilan dapat disebabkan oleh berbagai jenis plasmodium malaria namun plasmodium falcifarum merupakan plasmodium berdampak buruk yang dapat meningkatkan angka kesakitan dan kematian ibu serta berdampak buruk terhadap bayi dalam kandungan (Rahmawati, 2016).

Menurut data Dinas Kesehatan Papua tahun (2012) jumlah ibu hamil yang menderita malaria meningkat.Dimana jumlah ibu hamil yang menderita malaria hampir mencapai 14 ribu. Sedangkan Menurut data penyakit malaria Dinkes Kota Jayapura pada tahun 2015 terdapat ibu hamil dengan malaria sebanyak $31 \mathrm{ibu}$ hamil dan meningkat pada tahun 2016 sebanyak 79 orang (Kemenkes RI,2016) dan berdasarkan data Puskesmas Sentani (2018) tercatat jumlah ibu hamil dengan positif malaria sebanyak 56 orang.

Faktor penyebab malaria menurut penelitian Watofa (2017) adalahdimana faktorlingkungan fisik (suhu, kelembaban, curah hujan, $\mathrm{pH}$ air, penggunaan lahan, dan kondisi fisik rumah) di wilayah Danau Sentani memiliki hubungan yang bermakna dalam mendukung perkembang biakan nyamuk Anopheles sehingga angka kejadian malaria di wilayah Kabupaten Jayapura masih cukup tinggi

Selain faktor penyebab yang diakibatkan oleh gigitan nyamuk, terjadinya malaria pada ibu hamil didukung oleh faktor resiko yang diakibatkan dari kurangnya pengetahuan pada ibu hamil dalam mencegah malaria. Hal ini sesuai dengan penelitian yang dilakukan oleh Lefaan(2013) bahwa faktor resiko kejadian malaria pada ibu hamil akibat dari rendahnya tingkat pendidikan, tingkat pengetahuan yang kurang, sikap yang negatif dan kurang kooperatif, serta adanya tempat perindukan nyamuk dan tempat pemeliharaan ternak.

Ibu hamil harus mempunyai kemampuan dalam melakukan pencegahan terhadap kejadian malaria.Kemampuan ibu hamil dapat dipengaruhi oleh tingkat pendidikan ibu.Pendidikan kesehatan merupakan salah satu upaya yang dapat diberikan dalam meningkatkan kesadaran, meningkatkan kemandirian serta meningkatkan kesehatan baik individu, kelompok, keluarga dan masyarakat (Setiawati, 2008).

Teori Model Roy merupakan konsep teori yang membahas tentang adaptasi manusiaAdanya stimulus dari lingkungan secara terus-menerus mengharuskan seseorang menberikan respons dan beradaptasi. Respons ini dapat berupa respons adaptif ataupun maladaptif dimana respon adaptif akan membantu manusia mencapai tujuan beradaptasi, yaitu untuk mempertahankan hidup, tumbuh, berkembang biak, menguasai serta transformasi seseorang dan lingkungannya 
sedangkan respon maladaptif yaitu kondisi dimana manusia gagal beradaptasi.

Keperawatan mempunyai tujuan yang unik untuk membantu upaya adaptasi seseorang dengan mengelola lingkungannya.Hasilnya adalah pencapaian tingkat kesejahteraan seseorang.(Roy \& Robert, 1982; Alligood, 2017)

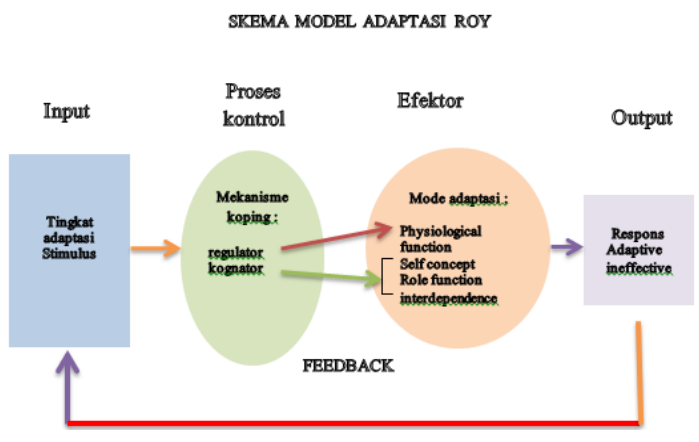

Pada penelitian ini adanya stimulus lingkungan yang berupa gigitan nyamuk mengharuskan ibu beradaptasi terhadap lingkungandengan melakukan pencegahan malaria.Dalam melakukan pencegahan malaria dibutuhkan adanya stimulus yang dapat meningkatkan pengetahuan dan merubah sikap serta perilaku sehingga menjadi adaptif.Untuk itu Paket MISERI yang merupakan paket pendidikan diharapkan dapat mendukung adaptasi dan sikap yang adaptif ibu hamil dalam melakukan pencegahan dini malaria.

Berdasarkan latar belakang di atas, peneliti ingin menguji keefektifan pemberian Pendidikan Kesehatan dalam bentuk "Paket MISERI" yang merupakan singkatan dari "Malaria Intervention Support Early Prevention" terhadap kemampuan ibu hamil dalam melakukan pencegahan dini malaria di Kabupaten Jayapura. Paket "MISERI" ini membahas tentang penyakit malaria, penyebab, cara penularan, efek malaria pada masa kehamilan serta cara mencegah terjadinya malaria dengan Paket MISERI.

Tujuan Umum ini adalah untuk mengetahui Efek "Paket MISERI" Terhadap Kemampuan Ibu Hamil Dalam Melakukan
Pencegahan Dini Malaria di Kabupaten Jayapura Papua.

Tujuan khusus

Tujuan Khusus ini adalah untuk mengetahui Efek "Paket MISERI" Terhadap Kemampuan Ibu Hamil Dalam Melakukan Pencegahan Dini Malaria di Kabupaten Jayapura Papua.T

Teridentifikasi karakteristik responden meliputi usia, pendidikan, ppekerjaan, suku bangsa di Puskesmas Sentani Jayapura.

Teridentifikasi perbedaan rata-rata pada kelompok intervensi sebelum dan sesudah diberikan intervensi "Paket MISERI" di Puskesmas Sentani Jayapura.

Teridentifikasi perbedaan rata-rata sebelum dan sesudah pada kelompok control yang tidak diberikan intervensi " Paket MISERI" Puskesmas Sentani Jayapura, Teridentifikasi perbedaan rata-rata sebelum dan sesudah pemberian "Paket MISERI" pada kelompok intervensi dan kelompok kontrol yang tidak diberikan "Paket MISERI". Puskesmas Sentani Jayapura.

\section{METODE}

Desain pada penelitian ini adalah penelitian kuantitatif dengan desain QuasiEksperiment pre and post with control groupdenganPopulasi semua ibu hamil yang ada di Wilayah Kerja Puskesmas Sentani.Pengambilan sampel yaitu dengan cara keseluruhan populasi yang masuk dalam kriteria inklusi yang sampelnya berjumlah minimal 35 responden pada kelompok perlakuan dan kontrol sehingga jumlah total sampel adalah 70 responden.

Penelitian ini dilakukan setelah mendapatkan persetujuan dari dewan peninjauan etik di Universitas Muhammadiyah Jakarta. Peneliti mengupayakan untuk selalu menjunjung etika penelitian, dengan menyakinkan bahwa responden akan terlindungi hakhaknya dengan memperhatikan berbagai aspek. 
Variabel yang diteliti adalah kemampuan ibu hamil dalam melakukan pencegahan dini malaria. Alat ukur yang digunakan yaitu menggunakan kuesioner yang terdiri dari kuesioner pengukuran pengetahuan, sikap dan perilaku.Pada kuesioner pengetahuan pertanyaan yang dibuat dengan jawaban Benar dan Salah apabila jawaban benar maka nilai nya 2 dan 1 apabila jawaban salah. Kemudian pada kuesioner sikap pernyataan dibuat menggunakan jawaban (SS) Sangat setuju dengan skor 4, (S) Setuju dengan skor 3, (TS) Tidak Setuju dengan skor 2, (STS) Sangat tidak Setuju dengan skor 1. Dan pada kuesioner observasi yang diisi oleh peneliti pernyataan dibuat menggunakan jawaban Iya dengan skor 2 jika dilakukan dan Tidak dengan skor 1 jika tidak dilakukan oleh responden.

Uji validitas pada pertanyaan yang digunakan pada item kuesioner dilakukan pada ibu hamil di Puskesmas Harapan Sentani Timur dengan kriteria yang sama dengan ibu hamil di Puskesmas Sentani Uji instrument dilakukan di Puskesmas Harapan Sentani Timur terhadap 20 reponden maka didapatkan $\mathrm{r}$ tabel yaitu $0,4438(\mathrm{df}=\mathrm{n}-220$ $2=18$, dengan sig5\%) didapatkan hasil dari 31 pertanyaan ada 1 pertanyaan mengenai pengetahuan dan 1 pertanyaan di sikap yang tidak valid kemudian dengan merubah kalimat pertanyaannya peneliti melakukan uji vaiditas kembali terhadap pertanyaan yang tidak valid hingga seluruh pertanyaan dinyatakan valid.

Berdasarkan uji realibilitas terhadap kuesioner ketentuan realibilitas yaitu pabila $\mathrm{r}$ Alpha > $\mathrm{r}$ tabel maka pertanyaan tersebut disebut reliabel. Dari hasil uji pernyataan pada nilai Alpha $(0,960)$ lebih besar dibanding nilai $r$ tabel $(0,4438)$.

$$
\text { Intervensi "Paket MISERI" }
$$

dilakukan oleh peneliti sendiri dimana proses pengambilan data pada kelompok intervensi yaitu ibu hamil di wilayah kerja Puskesmas Sentani yang memenuhi kriteria inklusi dimana pengelompokan kelompok intervensi adalah ibu hamil yang berdomisili di desa Sentani, Henekombe, Dobonsolo, Pos 7 dan Komba. Setelah itu membagikan kuesioner kepada responden, kemudian pemberian intervensi "Paket MISERI" dilakukan dengan mendatangi masingmasing rumah responden dan memberikan pendidikan kesehatan dengan menggunakan instrument penelitian berupa booklet Malaria Intervention Support Early Prevention \pm selama 15-20 menit Kemudian booklet tersebut diberikan kepada responden sebagai bahan bacaan. Setelah pemberian intervensi melakukan kunjungan rumah kembali di hari ke 7 untuk mengambil data post test.

Pada kelompok kontrol di Puskesmas Sentani yang memenuhi kriteria inklusi dimana pengelompokan kelompok intervensi adalah ibu hamil yang berdomisili di desa Hobong, Ifar Besar, Sereh, Yahim dan Yoke.Selanjutnya peneliti melakukan pretest dengan mendatangi masing-masing rumah responden untuk pengisian kuesioner Selanjutnya peneliti akan melakukan kunjungan rumah kembali di hari ke 7 untuk mengambil data post test. Setelah pengambilan data post test peneliti memberikan "Paket MISERI" terhadap kelompok kontrol sama seperti yang diberikan terhadap kelompok intervensi dan memberikan booklet sebagai bahan bacaan.Selanjutnya dilakukan analisis data.

Proses analisis data Analisis deskriptif dilakukan untuk mengetahui gambaran karakteristik responden selanjutnya untuk melihat perbedaan pada kelompok intervensi yang diberikan Paket MISERI dengan kelompok kontrol setelah kelompok intervensi diberi Paket MISERI maka menggunakan ujit-test berpasangan atau paired $t$ test. Data yang telah terkumpul diolah dengan menggunakan sistem komputer.

Sebelum dilakukan uji bivariate terlebih dahulu dilakukan uji normalitas data dengan menggunakan uji Shapirowilk. Dimana didapatkan $p$-value $>0,05$ yang menandakan bahwa data berdistribusi 
normal dehingga dapat dilanutkan dengan menggunakan ujipaired t test. pendidikan pekeraan suku dan agama pada kelompok intervensi dan kontrol.

\section{HASIL PENELITIAN}

\section{Analisis Univariat}

Analisi univariat pada penelitian ini memaparkan karakteristik responden berdasarkan usia, jenis kelamin, tingkat

\section{Tabel 1}

Distribusi karakteristik responden

\begin{tabular}{|c|c|c|c|c|c|}
\hline \multirow[t]{2}{*}{ Variabel } & \multirow{2}{*}{$\begin{array}{c}\begin{array}{c}\text { Intervensi } \\
\mathbf{N}=\mathbf{3 5}\end{array} \\
\mathbf{F} \\
\end{array}$} & \multicolumn{3}{|c|}{$\begin{array}{c}\text { Kontrol } \\
\mathrm{N}=35\end{array}$} & \multirow{2}{*}{$\begin{array}{c}\text { P Value } \\
\text { Uji Homogenitas }\end{array}$} \\
\hline & & $\%$ & $\mathbf{F}$ & $\%$ & \\
\hline \multicolumn{6}{|l|}{ Usia } \\
\hline $18-26$ & 22 & 62,9 & 21 & 59,9 & \multirow[b]{2}{*}{0,632} \\
\hline $27-35$ & 13 & 37,2 & 14 & 40,2 & \\
\hline Mean & 24,97 & & 25,43 & & \\
\hline Modus & 26 & & 20 & & \\
\hline Median & 25.00 & & 25.00 & & \\
\hline SD & 4.521 & & 4.132 & & \\
\hline Min-Max & $18-33$ & & $19-34$ & & \\
\hline \multicolumn{6}{|l|}{ Pendidikan } \\
\hline Rendah & 2 & 5,7 & 3 & 8,6 & \multirow{3}{*}{0,705} \\
\hline Menengah & 27 & 77,1 & 27 & 77,1 & \\
\hline Tinggi & 6 & 17,1 & 5 & 14,3 & \\
\hline \multicolumn{6}{|l|}{ Pekerjaan } \\
\hline Bekerja & 11 & 31,4 & 9 & 25,7 & \multirow{2}{*}{0,300} \\
\hline Tidak Bekera & 24 & 68,6 & 26 & 74,3 & \\
\hline \multicolumn{6}{|l|}{ Suku } \\
\hline Papua & 15 & 42,9 & 15 & 42,9 & \multirow{2}{*}{1,000} \\
\hline Non Papua & 20 & 57,1 & 20 & 57,1 & \\
\hline \multicolumn{6}{|l|}{ Agama } \\
\hline Islam & 17 & 48,6 & 16 & 25,7 & \multirow{2}{*}{0,300} \\
\hline Nasrani & 18 & 51,4 & 19 & 74,3 & \\
\hline \multicolumn{6}{|l|}{ Kemampuan } \\
\hline Pengetahuan & & & & & 0,022 \\
\hline Sikap & & & & & 0,930 \\
\hline Perilaku & & & & & 0,022 \\
\hline
\end{tabular}

Berdasarkan tabel Usiaibu hamil, pendidikan, pekerjaan, suku dan agama didapatkan hasil pada karakteristik usia rata-

rata responden kelompok intervensi yaitu 24,97 sedangkankelompok kontrol 25,43. Menurut pendidikan, yaitu rata-rata respondenkelompok intervensi dan kontrol sama banyak memiliki pendidikan menengah yaitu sebanyak $77,1 \%$. Menurut karakteristik pekerjaan responden tidak bekerja banyak pada kelompok intervensi yaitu sebanyak 26 orang (74,3\%). Kemudian pada distribusi karakeristik menurut suku pada kelompok intervensi dan kontrol memiliki jumlah yang sama yaitu suku papua sama-sama 15 orang $(42,9 \%)$ dan Non Papua sebanyak 20 orang $(57,1 \%)$.

Selanjutnya karakteristik responden menurut agama terbanyak dari masing-masing kelompok yaitu beragama nasrani dimana kelompok intervensi sebanyak 18 orang $(51,4 \%)$ dan kontrol dengan jumlah 19 $(54,3 \%)$. Kemudian pada hasil uji homogenitas distribusi frekwensi karakteritik bersifat homogen sebab memiliki hasil $>0,05$. 


\section{Analisis Bivariat}

Analisis bivariat dilakukan untuk mengetahui apakah ada perbedaan pengetahuan, sikap perilaku pada kelompok intervensi sebelum dan sesudah diberikan Paket MISERI serta untuk mengetahui apakah ada perbedaan pengetahuan sikap dan perilaku pada kelompok kontrol sebelum dan sesudah kelompok intervensi diberikan Paket MISERI.

Hasil perbedaan rata-rata kemampuan ibu hamil pada kelompok intervensi dapat dilihat pada Tabel 2

Tabel 2.Perbedaan rata-rata kemampuan ibu hamil dalam melakukan pencegahan dini malaria dengan Uji T Berpasangan variabel Pengetahuan, Sikap dan Perilaku Kelompok Intervensi Sebelum dan Sesudah diberikan Paket Miseri dan Kelompok kontrol yag tidak diberi paket Miseri

\begin{tabular}{|c|c|c|c|c|c|c|c|c|}
\hline \multirow{2}{*}{$\begin{array}{c}\text { Variabel } \\
\text { Kemampuan }\end{array}$} & \multicolumn{4}{|c|}{$\begin{array}{c}\text { Intervensi } \\
\mathrm{N}=35\end{array}$} & \multicolumn{4}{|c|}{$\begin{array}{c}\text { Kontrol } \\
\mathbf{N}=35\end{array}$} \\
\hline & Mean & SD & Selisih & pValue & Mean & SD & Selisih & pValue \\
\hline \multicolumn{9}{|l|}{ Pengetahuan } \\
\hline Pretest & 3.83 & 1.339 & \multirow{2}{*}{3,03} & \multirow{2}{*}{0,000} & 4.31 & 1.906 & \multirow{2}{*}{0,11} & \multirow{2}{*}{0.764} \\
\hline Post test & 6.86 & 1.958 & & & 4.20 & 2.084 & & \\
\hline \multicolumn{9}{|l|}{ Sikap } \\
\hline $\begin{array}{l}\text { Pretest } \\
\text { Post test }\end{array}$ & $\begin{array}{l}25.31 \\
39.91\end{array}$ & $\begin{array}{l}2.978 \\
3.043\end{array}$ & 14,6 & 0,000 & $\begin{array}{l}20.26 \\
21.34\end{array}$ & $\begin{array}{l}3.518 \\
3.497\end{array}$ & 1,08 & 0.213 \\
\hline Perilaku & & & & & & & & \\
\hline $\begin{array}{l}\text { Pretest } \\
\text { Post test }\end{array}$ & $\begin{array}{l}2.83 \\
5.86\end{array}$ & $\begin{array}{l}1.339 \\
1.958\end{array}$ & 3,03 & 0,000 & $\begin{array}{l}4.00 \\
4.20\end{array}$ & $\begin{array}{l}1.815 \\
1.891\end{array}$ & 0,2 & 0.663 \\
\hline
\end{tabular}

Berdasarkan Tabel 2 diketahui bahwa kelompok intervensi sesudah diberikan "Paket MISERI" berpengaruh secara bermakna dibanding kelompok kontrol yang tidak diberi paket MISERI pencegahan dini malaria dalam hal kemampuan pengetahuan sikap dan perilaku dimana mendapat hasil $\mathrm{p}$ value $=0,000 .<0,05$, hal ini dapat membuktikan bahwa "Paket MISERI" memiliki pengaruh terhadap peningkatan pengetahuan, sikap dan perilaku terhadap kelompok intervensi dalam melakukan pencegahan dini malaria pada ibu hamil.Sedangkan pada kelompok kontrol menunjukkan perubahan yang tidak bermakna dalam melakukan pencegahan dini malaria sebab di dapatkan $\mathrm{p}$ value > 0,05 .

\section{PEMBAHASAN}

Terbanyak pada penelitian ini adalah dengan rentang usia antara 18-26 tahun sebanyak 22 orang $(62,9 \%)$ pada kelompok intervensi dan 21 orang $(59,9 \%)$ pada kelompok intervensi. Dimana diusia tersebut masuk dalam kategori usia produktif dimana seorang wanita mampu bereproduksi. Hal ini sesuai dengan pendapat Sulistiawati (2011) bahwa rentang usia 20-35 tahun merupakan usia produktif bagi wanita yang dianggap aman untuk menjalani proses kehamilan dan persalinannya. Namun ibu hamil Didaerah endemis malaria, termasuk dalam kelompok yang beresiko atau rentan terhadap infeksi malaria sehingga membutuhkan adanya pencegahan dini malaria. Hal ini sejalan dengan penelitian yang dilakukan oleh Rusjdi (2012) bahwa ibu hamil didaerah endemis beresiko mengalami malaria dibandingkan dengan wanita yang tidak hamil.

Hasil penelitian memberikan gambaran bahwa Responden dengan pendidikan menengah lebih banyak dibanding responden yang berpendidikan rendah dan tinggi dengan jumlah 27 orang $(77,1 \%)$. Pendidikan erat kaitannya dengan pengetahuan sehingga memungkinkan seseorang akan mudah menerima suatu informasi yang diterima dalam menentukan pengambilan keputusan dan berpengaruh terhadap perilaku seseorang Sukarni \& Wahyu (2013). Sesuai dengan teori bahwa 
tingkat pendidikan berpengaruh terhadap pemberantasan malari, dimana pendidikan yang rendah dapat menyebabkan kurangnya pengetahuan sehingga pemahaman tentang pemberantasan malaria juga kurang, hal ini dapat memperburuk tindakan masyarakat dalam memberantas penyakit malaria (Maun, 2017).

Penelitian ini didapatkan hasil bahwa ratarata responden yang tidak bekerja lebih banyak dibanding dengan responden yang bekerja. Menurut Penelitian yang dilakukan oleh Suharjo et al. (2009) bahwa tingkat mobilitas penduduk dari daerah endemis mempengaruhi penularan malaria malaria import di suatu daerah. Adanya hubungan pekerjaan dengan kejadian malaria dengan risiko terjadinya malaria sebesar 0,048 kali lebih besar pada orang yang bekerja dibandingkan dengan orang tidak bekerja.Karena dalam penelitian ini responden rata-rata tidak bekerja maka Tidak terdapat keterkaitan dalam hal pekerjaan terhadap malaria. Pada distribusi karakteristik menurut suku pada kelompok intervensi dan kontrol memiliki jumlah yang sama dimana responden suku papua samasama 15 orang dan Non Papua sebanyak 20 orang.Suku juga memiliki kaitan erat terhadap faktor penyebab malaria pada masyarakat etnis papua sebab masyarakat papua memiliki kebiasaan untuk sering berada diluar rumah pada malam hari menurut ester dalam penelitiannya tentang "Perilaku Etnis Papua Mengenai Penyakit Malaria Di Kabupaten Nabire Papua" berada diluar rumahakan meningkatkan terjadinya resiko malaria sebab nyamuk malaria menggigit pada malam hari. Hal ini didukung oleh penelitian yang dilakukan oleh Sandy (2016) tentang "Survei Entomologi Anopheles spp di Kampung Bikar dan Kampung Kwor Kabupaten Tambrauw, Papua Barat"dimana Anopheles mulai aktif menggigit pada pukul 19.00-20.00 WIT dan mencapai puncak kepadatan pukul 23.0024.00 WIT malam hari.
Pada karakteristik agama dalam penelitian ini kebanyakan responden beragama nasrani di banding agama islam baik pada kelompok intervensi maupun kelompokkontrol. Agama dapat memberi dampak yang cukup berarti dalam kehidupan manusia, termasuk terhadap kesehatan.

Kesehatan seseorang dapat dinilai dari kemampuan orang tersebut dalam penyesuaian diri terhadap lingkungannya sebab hidup adalah proses penyesuaian diri terhadap seluruh aspek kehidupan, orang yang tidak mampu beradaptasi dengan lingkungannya maka akan mengalami kegagalan dalam menjalani kehidupannya (Hamid, 2017) termasuk hal nya dalam melakukan pencegahan malaria maka perilaku seseorang ternyata didukung oleh factor agama atau regiliusitas, salah satunya yaitu melakukan pencegahan malaria dengan menjaga lingkungan agar tetap bersih sebagaimana menurut agama Islam bahwa kebersihan adalah sebagian dari iman.

Hal ini Sesuai penelitian yang dilakukan oleh Yanuarti (2018) bahwa Sikap religiusitas memiliki pengaruh terhadap perilaku bersih masyarakat,. Kemudian dimensi konsekuensi beragama masyarakat membawa pengaruh terhadap perilaku masyarakat

Efek "paket miseri" terhadap kemampuan ibu hamil dalam melakukan pencegahan dini malaria hasil dari penelitian ini membuktikan adanya efek Paket MISERI setelah dilakukan intervensi. Hal tersebut dapat dilihat dari hasil pengolahan data penelitian yang menunjukkan bahwa terjadi peningkatan kemampuan pengetahuan, merubah sikap dan perilaku pada kelompok intervensi dimana kelompok intervensi memiliki kesadaran bahwa mencegah malaria terutama dimasa kehamilan itu sangat penting agar ibu hamil terhindar dari malaria serta efek buruk dari terjadinya malaria sehingga ibu hamil dapat 
menjalankan kehamilannya dengan aman tanpa malaria.

Wanita hamil lebih rentan terhadap infeksi malaria dibandingkan dengan wanita yang tidak hamil. Hal ini berkaitan dengan proses imunologi dan perubahan hormonal selama kehamilan terutama hormon progesteron dan kortisol dimana peningkatan hormon progesteron ini mengakibatkan terhambatnya aktifasi limfosit $T$ terhadap stimulasi antigen sehingga mengkibatkan banyaknya eritrosit yang terinfeksi parasit pada intervillus plasenta. Selain itu tubuh ibu hamil menangkap bahwa keberadaan fetus dianggap sebagai "benda asing" sehingga mengakibatkan sistem imun ibu hamil mengalami perubahan (Rusjdi, 2012).

Paket MISERI merupakan paket pendidikan dengan menggunakan media booklet yang berisi tentang penyakit malaria, penyebab, tanda dan gejala, komplikasi pada ibu hamil dan janin, serta membahas tentang pencegahan dini terhadap malaria dengan menggunakan metode MISERI yang konsepnya berasal dari pemerintah dan penelitian terkait.

Sesuai teori Pendidikan kesehatan merupakan proses dari tidak tahu menjadi tahu dan dari tidak mampu mengatasi masalah kesehatan sendiri menjadi mandiri. Sehingga pendidikan kesehatan dapar meningkatkan pengetahuan, sikap maupun keterampilan agar tercapai hidup sehat secara optimal (Nasution, 2004: Apilaya, 2016).

Teori Model Roy merupakan konsep teori yang membahas tentang adaptasi manusia.Dimana didalamya berhubungan dengan keperawatan, manusia, kesehatan, dan lingkungan yang antara satu dengan lannya saling berkaitan. Manusia mengalami stimulus lingkungan secara terus-menerus yang mengharuskan seseorang menberikan respons dan beradaptasi .(Roy \& Robert, 1982; Alligood, 2017).

Pada masyarakat di wilayah endemis malaria akan terpapar dengan resiko terjangkit penyakit malaria terutama ibu hamil yang beresiko lebih besar mengalai malaria dibandingkan ibu yang tidak hamil. Sebagai stimulus fokal yaitu adanya gigitan nyamuk anopheles betina penyebab malaria.Dengan diberikannya "Paket MISERI" pada sistem kontrol.terbukti menstimulasi ibu hamil pada Stimulus Kontekstual dalam meningkatkan pengetahuan, merubah sikap dan perilaku untuk melakukan pencegahan dini malaria. Dan menghasilkan output yang baik dimana ibu mampu melakukan pencegahan malaria.

Dari hasil diatas maka disimpulkan bahwa terdapat efek "Paket MISERI" setelah dilakukan intervensi, hal ini dapat dilihat dari hasil penelitian yang menunjukkan bahwa responden kelompok intervensi mengalami peningkatan pengetahuan, sikap, dan perilaku dalam melakukan pencegahan dini malaria dibandingkan dengan kelompok kontrol.

Saran bagi pelayanan keperawatan perlunya membuat program promosi kesehatan yang dilakukan secara continue terhadap ibu hamil di wilayah endemis malaria menggunakan "Paket MISERI" dalam pencegahan dini malaria.Serta memfasilitasi perawat untuk mengembangkandiri guna meningkatkan promosi kesehatan terkait pencegahan dini malaria pada ibu hamil.

Bagi institusi pendidikanPenelitian ini dapat dijadikan Evidence Based Practice sebagai bahan ajar mengenai pencegahan malaria pada ibu hamil

Bagi peneliti selanjutnya penelitian ini dapat dijadikan dasar untuk melakukan penelitian yang lebih lanjut dengan pengambilan random sampling atau dengan melakukan penelitian kualitatif tentang budaya dan perilaku masyarakat sentani dalam melakukan pencegahan dini malaria pada ibu hamil.

\section{UCAPAN TERIMAKASIH}

Penulis mengucapkan Terimakasih kepada:

1. Dr. Muhammad Hadi, SKM., M.Kep Selaku Dekan FIK UMJ 
2. Dr. Tri Kurniati, SKp., M.Kes Selaku Ketua Program Study Magister

3. Dr. Irna Nursanti., M.Kep., Sp.MatSebagai pembimbing I

4. Dr.dr. M. Natsir Nugroho, Sp.OG, M.Kes Sebagai Pembimbing II.

\section{REFERENSI}

Aulia A.R (2015). Hubungan Perilaku Hidup Sehat Dengan Kejadian Malaria Di Wilayah Kerja Puskesmas Kota Sorong Papua Barat.Surakarta: Universitas Muhammadiyah Surakarta.

Alligood,M.R.(2017).Nursingtheorist And Theirwork.Missouri: Mosby Elsevier

Depkes.(2016). Data Kejadian Malaria DI Kota Jayapura.Jayapura :Departemen Kesehatan RI.

Ester, (2013).Perilaku Etnis Papua Mengenai Penyakit Malaria Di Kabupaten Nabire Papua.Skripsi.Jayapura: Program Studi Keperawatan Nabirepoliteknik Kesehatan Jayapura

Hermawan D. (2016).Hubungan Keberadaan Tempat Perindukan Nyamuk Dan Tingkat Pengetahuan asyarakat Terhadap Kejadian Malaria di Desa Sukajaya Lempasing Kabupaten Pesawaran Provinsi Lampung Tahun 2015. J Medika Malahayati.3(4):1906

Dinkes Kabupaten Jayapura. (2012). Profil dinas kesehatan kabupaten Jayapura

Kapitan.M. (2013).Pengaruh "Paket Ibu Sehat" Terhadap Pengetahuan Dan Perilaku Mengatasi Gejala Klinis Saat Serangan Malaria Pada Ibu Hamil Di Kabupaten Sumba Barat

Daya.Jakarta:UniversitasIndonesia

Lefaan, A.M.(2011). Faktor Risiko yang Berhubungan dengan Kejadian Malaria pada Ibu Hamil di Puskesmas Tawiri Kecamatan Baguala Kota Ambon Provinsi
Maluku Periode 2009-2011 [Skripsi].

Makassar: Universitas Hasanuddin;2011.

Maun.R.M. (2017).Penaruh Penyuluhan Terhadap Pencegahan malaria Pada Keluarga di Desa Wiau Lapi Kecamatan Tareran E-Jurnal Sariputra Vol. 4 (2)

Rusjdi, S.R .(2012). Malaria Pada Masa Kehamilan Jurnal Kedokteran Andalas No.2.Vol.36.

Rahmawati, (2014) Determinan Kejadian Pada Ibu Hamil Di Papua Barat Jurnal MKMI:166-173

Watofa.(2017). Risiko Lingkungan Fisik Terhadap Kejadian Malaria di Wilayah Danau Sentani, Kabupaten Jayapura, Provinsi Papua. Jurnal manusia \& lingkungan vol. 24 , no. 1

Suparman, E., \& Suryawan, A. (2014).Malaria pada kehamilan.JKM Vol.4(1): 21-39

Setiawati, S. 2008. Proses Pembelajaran Dalam Pendidikan Kesehatan.Jakarta : Trans Info Media 